\title{
A touch on the tiller
}

There are a few who read every page in the Archives, but most do not. The usual reader will look through the list of contents, glance through a few of the summaries that may be of interest, and if those are tempting enough perhaps read the complete articles. In the past we used to consider that all the papers published should be of interest to a practising clinical paediatrician. With the advance in paediatric science this has become an unrealistic aim. It has also resulted in some paediatricians sending their work to specialist organ journals which are either predominantly adult, or to the small paediatric specialty journals, (both of which have circulations and readerships far below those of a well established general paediatric journal such as ours). We are continuing to increase the size and the scope of our journal. We shall deliberately accept a small number of more specialised papers provided that they are of high scientific standard and potential importance. We are prepared to accept papers on pure laboratory observation, including animal work which is relevant to the care of children in health or disease. We know that some of these papers will appeal only to a minority of our readers but we will ensure that each specialty is represented and that within each issue there is something of interest for all paediatricians whether they be generalists or sub-specialists.

\section{Correspondence columns}

Recently the New England Journal of Medicine published a letter that challenged the authenticity of a figure in a paper which had been published 12 years previously. The doctor who provided the figure admitted that it was produced as a teaching illustration and was not a genuine recording as the authors had implied. The figure was produced by a laboratory based doctor who was not one of the authors of the article. The editor regretted that the 'editors of the journal, like the authors of the article, failed to recognise that the tracing had been fabricated'. The authors of the letter were the first to point out, in the correspondence columns, that the work could not be reproduced, although the technique was in current use and several hundreds if not thousands of patients had had operations as a result of recordings of that type.

Who is to blame? The editor has frankly accepted some blame but what about the numerous investigators who had carried out these tests on patients for the previous 12 years and it seems were unable to reproduce the findings? Surely they had an obligation to write to the journal to point it out? Had the prestige of the journal or the authors become so overwhelming that the game of the 'Emperor's New Clothes' had to be perpetuated? Were these investigators worried about being ridiculed in public or of the letter not being accepted by the editors?

It is the responsibility of every investigator to report to his colleagues if he cannot reproduce published work. This may be because he has not followed the details of the original report carefully, insufficient details were given in the paper, or the original results were faked. If the last is correct the sooner it is broadcast the better. Fruitless future research will be prevented. On the other hand, it is well known by professional research workers that unexpected or discrepant results may lead to the discovery of principles of greater importance than the original hypothesis. We hope you will be encouraged to write to us about your thoughts on the papers we have published. We shall try to publish as many letters as space allows but will use the same criteria of originality and sound science that we use for original articles.

\section{Repetitive publication}

Authors have submitted and had published essentially the same articles in separate journals without the editors' knowledge. The editor of the Annals of Internal Medicine has listed various sorts of dishonesty among authors. That journal has adopted a set of conditions for publication which all authors have to agree and sign. The British Medical Journal intends to expose duplicated articles by means of a formal notice that will warn readers that the papers are similar. The editor of the Journal of General Microbiology has stated that no manuscripts submitted by offending authors to that journal or any other journal of the American Society of Microbiology 


\section{Editorial policy}

will be considered for three years. We will try to avoid repetitive publication.

\section{Instructions to authors}

New instructions to authors are published in this issue (page 90), will be reprinted in January and June each year, and are available as a reprint from the editorial office. Papers which are not accepted for publication will not be returned to authors unless this is requested in the covering letter. Detailed suggestions are given for letters.
Although we have pointed out that every author on a paper should have made a special contribution in thought or deed beyond his routine work, ${ }^{1}$ we still receive simple case reports with eight or more alleged authors. One useful guideline is that an author should be capable of presenting the paper at an international scientific meeting.

\section{Reference}

1 Anonymous. Et alia [Editorial]. Arch Dis Child 1980;55:749. 